\title{
Intracisternal or intrathecal glycine, taurine, or muscimol inhibit bicuculline-induced allodynia and thermal hyperalgesia in mice
}

\author{
II-ok LEE ${ }^{1, *}$, Eui-sung LIM² \\ ${ }^{1}$ Departments of Anesthesiology and Pain Medicine, College of Medicine, Korea University, Seoul, Republic of Korea; ${ }^{2}$ Anesthesiologist, \\ Departments of Anesthesiology and Pain Medicine, College of Medicine, Korea University, Seoul, Republic of Korea
}

\begin{abstract}
Aim: To investigate the effects of GABA and glycine on analgesia in the central nervous system.
Methods: Glycine, taurine, or muscimol was injected with bicuculline into the cistern magna or the lumbar subarachnoidal space in ICR mice. The effects on bicuculline-induced allodynia in a touch-evoked agitation test and on pain threshold index in a hot-plate test were assessed.

Results: The dosages of the amino acids administered with bicuculline had no effect on motor behavior in conscious mice. Glycine or muscimol reduced bicuculline-induced allodynia regardless of the administration site, whereas intrathecal taurine reduced bicucullineinduced allodynia. Glycine, taurine, and muscimol all antagonized the effects induced by bicuculline in the hot-plate test, regardless of the administration site.

Conclusion: Glycine, taurine, and muscimol were found to have anti-allodynic and anti-thermal hyperalgesic properties in vivo. These observations suggest an interaction between glycine and GABA receptors during the regulation of antinociception.
\end{abstract}

Keywords: allodynia; hyperalgesia; bicuculline; glycine; intracisternal; intrathecal drug delivery

Acta Pharmacologica Sinica (2010) 31: 907-914; doi: 10.1038/aps.2010.82

\section{Introduction}

$\mathrm{Y}$-Aminobutyric acid (GABA) and glycine are important inhibitory neurotransmitters in the mammalian central nervous system $(\mathrm{CNS})^{[1]}$. The activation of glycine receptors typically yields an anti-nociceptive response ${ }^{[2]}$. However, the acute antagonism of spinal $\mathrm{GABA}_{\mathrm{A}}$ receptors exhibited by bicuculline produces touch-evoked agitation (allodynia) $)^{[3]}$.

GABA and glycine are colocalized in interneurons in spinal laminae I-III ${ }^{[4,5]}$ and are coreleased from the same interneurons $^{[6]}$. However, taurine binds to glycine receptors in the CNS and functions as a partial agonist of $\mathrm{GABA}_{\mathrm{A}}$ receptors ${ }^{[7]}$, inhibiting behaviors evoked by intrathecal $N$-methyl- $D$-aspartate (NMDA) or kainate injection ${ }^{[8,9]}$.

If GABA and glycine are coreleased from the same interneurons, and glycine-related amino acids act at GABA and glycine receptors to modulate low-threshold transmission via distinct but complementary mechanisms, then glycine or its related amino acids might inhibit bicuculline-induced allodynia.

\footnotetext{
* To whom correspondence should be addressed. E-mail iloklee@korea.ac.kr

Received 2010-01-25 Accepted 2010-06-10
}

However, the nature of the interaction between glycine and GABA during sensory modulation is unclear.

We undertook this study with the following objectives. First, we wanted to determine whether central glycine, taurine, or muscimol $\left(\mathrm{GABA}_{\mathrm{A}}\right.$ receptor agonist) can produce analgesia. Second, we wanted to know whether glycine, taurine, or muscimol can antagonize bicuculline-induced allodynia and heat hyperalgesia.

\section{Materials and methods \\ Animals}

This study was conducted after obtaining approval from the Animal Care Committee of Korea University. Male ICR mice weighing 23-27 g were housed one per cage before experiments in an environmentally controlled room $\left(22 \pm 2{ }^{\circ} \mathrm{C}\right.$, relative humidity $55 \% \pm 5 \%$ ) under a $12 \mathrm{~h}: 12 \mathrm{~h}$ light cycle (lights on at 7:00 am) with free access to food and water.

\section{Drugs}

Solutions were prepared in artificial cerebrospinal fluid (aCSF) containing (in mmol/L): $124 \mathrm{NaCl}, 26 \mathrm{NaHCO}_{3}, 1.25 \mathrm{NaH}_{2} \mathrm{PO}_{4}$, $2.5 \mathrm{KCl}, 2 \mathrm{MgCl}_{2}, 2 \mathrm{CaCl}_{2}$, and 10 dextrose. The solution $\mathrm{pH}$ 
was 7.3-7.4, and its average osmolality was about $300 \mathrm{mOsm}$. Drugs were dissolved in sterile saline on experimental days and stored on ice until use. Immediately prior to use, drugs were diluted to the required concentrations with aCSF. Glycine, taurine, bicuculline, and muscimol were purchased from Sigma (St Louis), and sevoflurane was purchased from Abbott Laboratories Limited (Queenborough, Kent, UK).

\section{Intracisternal injections}

Anesthesia was induced using $4 \%$ sevoflurane in air in a $500-$ $\mathrm{mL}$ induction chamber. A rubber facemask was used to maintain anesthesia (sevoflurane $4 \%$ through a Mapleson D circuit) and to immobilize the mouse's head. In addition, mice were placed in a holder molded from modeling clay to fit the body. A space was molded in the posterior neck area to allow the region between the occiput and atlas to be palpated as well as to facilitate injection. Intracisternal injections were performed using a $25-\mu \mathrm{L}$ Hamilton syringe (Hamilton Co, NV, USA) attached to a 27-G stainless steel needle, the tip of which was modified with a stopper to ensure an insertion depth of 2.4 $\mathrm{mm}$. The needle was carefully advanced to the cistern magna; after the injection had been made, the syringe was held in position for a few seconds and then gradually removed to avoid drug outflow along the needle tract. Injection sites were verified by injecting a similar volume of $1 \%$ methylene blue solution and then confirming the distribution of dye in the cisternal space. Throughout the experiment, the dye was found to distribute throughout the cistern magna space and to reach the occipital surface of the brain and the upper cervical portion of the spinal cord. The experimenter was trained using dye injections prior to beginning the experiments and achieved an accuracy of $\geq 98 \%$ in other mice. The entire injection procedure, including anesthesia, took about three min. Spontaneous face scratching or touch-evoked allodynia of the face was observed after the injection of bicuculline.

\section{Intrathecal injection}

All intrathecal injections were made at the L5-L6 intervertebral space using a 30 -gauge 0.5 -inch needle mounted on a $25-\mu \mathrm{L}$ Hamilton syringe, as previously described by Hylden and Wilcox ${ }^{[10]}$. Injection sites were verified by injecting a similar volume of $1 \%$ methylene blue solution and determining the distribution of the dye in the spinal cord. In this case, the dye was distributed rostrally and caudally but over a short distance (less than $1 \mathrm{~cm}$ ). No dye was found in the brain. The experimenter was similarly trained using dye prior to experiments, and achieved an accuracy of $\geq 95 \%$. The entire injection procedure, including handling, also took about three minutes. Spontaneous tail-biting as well as touch-evoked allodynia of hind feet and tail was observed after mice were injected with bicuculline.

\section{Experimental protocol}

To examine the effects of different doses of bicuculline, $5 \mu \mathrm{L}$ of bicuculline at concentrations of $2.5 \mu \mathrm{mol}(0.0045925 \mu \mathrm{g})$,
$5 \mu \mathrm{mol}(0.009185 \mu \mathrm{g}), 7.5 \mu \mathrm{mol}(0.0137775 \mu \mathrm{g})$, or $20 \mu \mathrm{mol}$ $(0.03674 \mu \mathrm{g})$ was injected intracisternally or intrathecally. Two of the four mice treated with $0.0045925 \mu \mathrm{g}$ of bicuculline administered intracisternally failed to show allodynia to light touch. However, $0.009185 \mu \mathrm{g}$ administered intracisternally induced consistent touch-evoked allodynia, and two mice of the four mice treated with $0.03674 \mu \mathrm{g}$ exhibited convulsive behavior (body rollover, loss of postural control, falling, motor arrest with myoclonic jerks, and frequent dyskinesia) ${ }^{[11,12]}$. Accordingly, we chose to use $0.009 \mu \mathrm{g}$ of bicuculline to induce allodynia in all subsequent experiments.

To determine the appropriate dose of muscimol, we injected $5 \mu \mathrm{L}$ at concentrations of $0.025 \mathrm{mmol}(0.0142625 \mu \mathrm{g}), 0.05 \mathrm{mmol}$ $(0.028525 \mu \mathrm{g}), 0.25 \mathrm{mmol}(0.142625 \mu \mathrm{g}), 0.5 \mathrm{mmol}(0.28525$ $\mu \mathrm{g})$, or $5 \mathrm{mmol}(2.8525 \mu \mathrm{g})$. Mice administered $0.28525 \mu \mathrm{g}$ intracisternally were sedated for more than $4 \mathrm{~min}$ or showed intermittent dyskinetic hyperactivity; we were unable to perform the hot-plate test on these mice. Mice administered $2.8525 \mu \mathrm{g}$ of muscimol intrathecally showed paresis of both hind limbs for more than $2 \mathrm{~h}$. Finally, we chose muscimol doses of $0.01,0.02$, and $0.1 \mu \mathrm{g}$ for subsequent experiments.

Similarly, preliminary experimentation indicated that analgesic doses of $25 \mu \mathrm{g}$ for glycine and of $40 \mu \mathrm{g}$ for taurine (the molar equivalent of the glycine $25 \mu \mathrm{g}$ dose $(66 \mathrm{mmol})$ ) were optimal for both intracisternal and intrathecal injections. The dosages of glycine, taurine, muscimol, and bicuculline used had no effect on motor behavior in conscious mice.

\section{Study design}

Experiments were performed in a blinded and randomized fashion. The experimenter who injected the drug and the observer were unaware of which drug had been administered. Drug and control solutions were injected in a random, computer-generated order (http://www.randomizer.org). Animals were subjected to one treatment only. Allodynia and hot-plate test sessions were conducted for $60 \mathrm{~min}$ after drug injections. Experiments were conducted between 9:00 am and 4:00 pm in a quiet room.

The mice were divided into two main experimental groups: the allodynia test group and the hot-plate test group. Control mice were given $5 \mu \mathrm{L}$ of bicuculline $(n=8)$ or aCSF as vehicle $(n=8)$ only. The two experimental groups were divided randomly in subgroups: vehicle control $(n=8)$, glycine $(5,10$, or $25 \mu \mathrm{g})(n=8$, per dosage), taurine $(10,20$, or $40 \mu \mathrm{g})(n=8$, per dosage), and muscimol $(0.01,0.02,0.1 \mu \mathrm{g})(n=8$, per dosage). Each mouse in the experimental groups received bicuculline in combination with one of the study drugs above. When the combined effects of drugs were examined, the drugs were coadministered intracisternally or intrathecally to ensure their co-localization and to minimize injection volumes. After injections, mice in the allodynia test group were placed individually in transparent plastic cages $(30 \mathrm{~cm}$ long, $15 \mathrm{~cm}$ high, and $15 \mathrm{~cm}$ wide) for observation, whereas mice in the hot-plate test group were placed on a clear glass plate. Timing started after injections were complete. 


\section{Allodynia test}

We tested for allodynia using a paintbrush by touching face fur (after intracisternal injection) or hind foot or tail bare skin (after intrathecal injection) in a rostro-caudal sequence (face, hind foot, tail).

These stimuli in treatment naive or vehicle (aCSF)-control mice were insufficient to cause scratching or attempts to escape. Behavioral responses were quantified by a second experimenter. Touch-evoked agitation was checked every 5 min until 60 min after drug injection. Normal quiescent behavior, that is, grooming, sniffing, and exploring the environment, was not included. Touch-evoked agitation was ranked as described by Minami et $a l^{[13]}$ : $0=$ no response; $1=$ mild squeaking with attempts to move away from the probe; and 2=vigorous squeaking, biting of the probe, vigorous scratching, tail flicking, or biting of the tail and vigorous attempts to avoid the probe. Values are the averages of total scores at each time point (maximal possible score at each time point $=2 /$ mouse). Allodynia scores were calculated by summing the numbers of positive responses every $5 \mathrm{~min}$ for $60 \mathrm{~min}$. This overall test time was chosen based on the findings of preliminary studies; these studies showed that touchevoked behavioral responses continued for $45 \mathrm{~min}$ after the injection of bicuculline and gradually diminished thereafter. All experiments were recorded using a video camera (Sony) and then saved to computer file.

\section{Hot-plate test}

Mice were allowed to acclimate within an acrylic enclosure on a clear glass plate before the experiment. A radiant heat source was then focused onto the plantar surface of a hind paw. The test involved placing a mouse on a hot plate maintained at $55{ }^{\circ} \mathrm{C}$ and recording the time to first response (foot licking, jumping, or rapidly removing paws), as described by Minami et $a l^{[14]}$. A timer stopped automatically when withdrawal of the paw was detected by a photodetector (a cut-off value of $30 \mathrm{~s}$ was used to prevent tissue damage). Response times were measured twice at 5-min intervals and mean values were considered as pain thresholds. Basal pain thresholds were measured before drug administration (time $=0$ ). Responses were observed at 15, 30, 45, and 60 min after drug injection. These times were chosen based on the results of preliminary studies, which showed that hot plate response peaked between 30 and $45 \mathrm{~min}$ after the injection of bicuculline.

For analysis purposes, all response latencies were expressed as hot-plate test pain indices (HPPI) where:

$$
\mathrm{HPPI}=\frac{\text { Pain threshold by the hot-plate test }}{\text { Basal pain threshold by the hot-plate test }}
$$

\section{Sedation assay}

A mouse was placed on a rubber cylinder (height $2.5 \mathrm{~cm}$, diameter $6 \mathrm{~cm}$ ) after drug or vehicle administration ${ }^{[15]}$. We recorded the time that elapsed before the mouse jumped off the rubber cylinder. When time taken to step off the rubber was longer than that observed among controls, sedation had been achieved.

\section{Statistical analysis}

Sedation results were analyzed using the binomial test. Allodynia scores or hot-plate test results were analyzed by ANOVA (analysis of variance). Post-hoc analysis was performed using Dunn's test or Holm-Sidak methods. Student's two-tailed test was used to compare two means. The level of significance was set at $5 \%(P<0.05)$. Data are presented as means \pm SEM. Statistical analysis was performed using SigmaStat 3.0 (Systat Software Inc, Chicago).

\section{Results}

Effects of glycine, taurine, or muscimol on bicuculline-induced allodynia

Treatment with glycine, taurine, or muscimol failed to induce significant allodynia at the doses used, and no significant difference was observed between the allodynia scores of experimental groups and the vehicle controls. Animals treated intracisternally or intrathecally with bicuculline had higher cumulative allodynia scores than animals treated with aCSF $(n=8, P<0.05$ vs aCSF vehicle controls, Figure 1$)$.
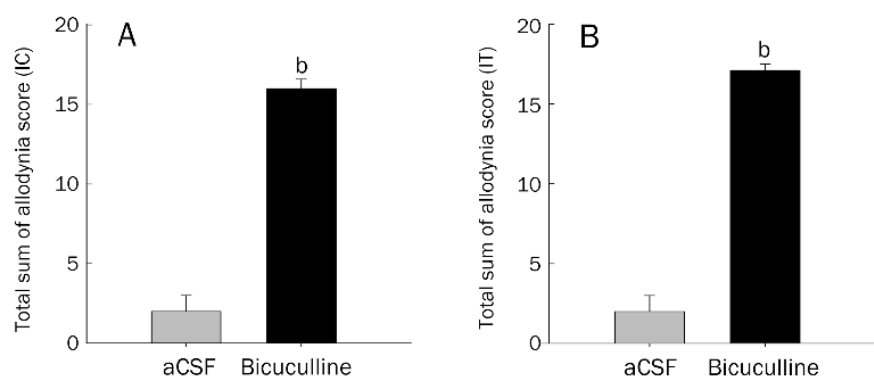

Figure 1. Effect of bicuculline or aCSF on touch-evoked allodynia in conscious mice. Bicuculline $(0.009 \mu \mathrm{g})$ or aCSF was injected intracisternally (IC, A) or intrathecally (IT, B). Data are expressed as means \pm SEMs. ${ }^{\mathrm{b}} P<0.05$ vs vehicle (aCSF) controls by the $t$-test $(n=8$ mice per group).

In the glycine, taurine, or muscimol+bicuculline groups, glycine $(25 \mu \mathrm{g})$ and muscimol $(0.1 \mu \mathrm{g})$ significantly reduced bicuculline-induced allodynia, regardless of administration site $(n=8, P<0.05$ vs bicuculline+aCSF). Furthermore, intrathecal taurine $(40 \mu \mathrm{g})$ significantly reduced bicuculline-induced allodynia $(n=8, P<0.05$ vs bicuculline + aCSF) (Table 1$)$.

\section{Effects of glycine, taurine, or muscimol on bicuculline-induced thermal hyperalgesia}

The basal latencies of conscious mice as measured by the hotplate test were similar before drug injection. Mice administered intracisternal glycine $(25 \mu \mathrm{g})$ alone had a higher HPPI at $15 \mathrm{~min}$ than at baseline (time=0); this value was also higher than that of vehicle controls $(P<0.05)$. When given alone, intrathecal glycine, taurine, or muscimol had no effect on the pain threshold index ( $P>0.05$ vs vehicle controls) (data not 
Table 1. Inhibitory effects of glycine, taurine, and muscimol on bicuculline-induced touch evoked allodynia in conscious mice.

\begin{tabular}{|c|c|c|c|c|c|}
\hline \multicolumn{6}{|c|}{ Intracisternal injection } \\
\hline Group & $(n=8$, each $)$ & Group & $(n=8$, each $)$ & Group & $(n=8$, each $)$ \\
\hline $\mathrm{B}+\mathrm{aCSF}$ & $16 \pm 1$ & $\mathrm{~B}+\mathrm{aCSF}$ & $16 \pm 1$ & $\mathrm{~B}+\mathrm{aCSF}$ & $16 \pm 1$ \\
\hline B+glycine $5 \mu \mathrm{g}$ & $15 \pm 1$ & B+taurine $10 \mu g$ & $14 \pm 1$ & $\mathrm{~B}+$ muscimol $0.01 \mu \mathrm{g}$ & $14 \pm 1$ \\
\hline $\mathrm{B}+\mathrm{glycine} 10 \mu \mathrm{g}$ & $14 \pm 1$ & B+taurine $20 \mu g$ & $14 \pm 1$ & $\mathrm{~B}+$ muscimol $0.02 \mu \mathrm{g}$ & $13 \pm 1$ \\
\hline B+glycine $25 \mu \mathrm{g}$ & $11 \pm 1^{b}$ & $\mathrm{~B}+$ taurine $40 \mu \mathrm{g}$ & $12 \pm 1$ & $\mathrm{~B}+$ muscimol $0.1 \mu \mathrm{g}$ & $9 \pm 1^{\text {be }}$ \\
\hline \multicolumn{6}{|c|}{ Intrathecal injection } \\
\hline Group & $(n=8$, each) & Group & $(n=8$, each $)$ & Group & $(n=8$, each $)$ \\
\hline $\mathrm{B}+\mathrm{aCSF}$ & $19 \pm 1$ & $\mathrm{~B}+\mathrm{aCSF}$ & $19 \pm 1$ & $\mathrm{~B}+\mathrm{aCSF}$ & $19 \pm 1$ \\
\hline $\mathrm{B}+\mathrm{glycine} 5 \mu \mathrm{g}$ & $15 \pm 2$ & B+taurine $10 \mu g$ & $15 \pm 2$ & $\mathrm{~B}+$ muscimol $0.01 \mu \mathrm{g}$ & $14 \pm 2$ \\
\hline B+glycine $10 \mu g$ & $15 \pm 2$ & B+taurine $20 \mu g$ & $15 \pm 2$ & $\mathrm{~B}+$ muscimol $0.02 \mu \mathrm{g}$ & $14 \pm 2$ \\
\hline $\mathrm{B}+$ glycine $25 \mu \mathrm{g}$ & $12 \pm 1^{b}$ & $\mathrm{~B}+$ taurine $40 \mu \mathrm{g}$ & $12 \pm 1^{\mathrm{b}}$ & $\mathrm{B}+$ muscimol $0.1 \mu \mathrm{g}$ & $8 \pm 2^{\text {be }}$ \\
\hline
\end{tabular}

Values are expressed as means \pm SEMs ( $n=8$ mice per group). Numbers are total sum of allodynia scores. Allodynia score was checked every 5 min for a 60 min after drug injection. Allodynia of faces was checked after an intracisternal injection of drug. Allodynia of the hindfoot or tail was checked after intrathecal injection of drug. B, bicuculline. ${ }^{b} P<0.05$ vs bicuculline+aCSF group. ${ }^{e} P<0.05$ vs bicuculline+muscimol $0.01 \mu$ g using one-way ANOVA, Dunn's test, or the Holm-Sidak method.

shown).

Intracisternal bicuculline decreased the HPPI from 15 to $45 \mathrm{~min}(P<0.05$ vs vehicle controls). Intrathecal bicuculline decreased the HPPI from 15 to $60 \mathrm{~min}(P<0.05$ vs vehicle controls), and decreased the HPPI from 15 to $45 \mathrm{~min}(P<0.05$ vs baseline) (Figure 2).

In the glycine, taurine, or muscimol+bicuculline groups, glycine (intracisternal $25 \mu \mathrm{g}$ or intrathecal 10, $25 \mu \mathrm{g}$ ) increased the HPPI ( $P<0.05$ vs bicuculline+aCSF) (Figure 3A, 3B). Taurine (intracisternal $40 \mu \mathrm{g}$ or intrathecal 20,40 $\mu \mathrm{g}$ ) increased the HPPI ( $P<0.05$ vs bicuculline+aCSF group) (Figure $4 \mathrm{~A}, 4 \mathrm{~B})$. Similarly, muscimol (intracisternal $0.1 \mu \mathrm{g}$, or intrathecal 0.02, $0.1 \mu \mathrm{g})$ also increased the HPPI $(P<0.05$ vs bicuculline+aCSF group) (Figure 5A, 5B).

In the glycine, taurine, or muscimol+bicuculline groups, intracisternal glycine, taurine, or muscimol increased the HPPI at $60 \mathrm{~min}(P<0.05$ vs baseline) (Figure 3A, 4A, 5A). In the glycine, taurine, or muscimol+bicuculline groups, intracisternal muscimol increased the HPPI at $45 \mathrm{~min}(P<0.05$ vs baseline), and intrathecal muscimol or taurine increased the pain threshold from 15 to $60 \mathrm{~min}(P<0.05$ vs baseline) (Figure 4B, 5B). The intrathecal administration of muscimol and taurine had more prolonged anti-hyperalgesic effects than did intracisternal administration, as determined by the hot-plate test (Figure 4, 5).

\section{Side effects of glycine, taurine, and muscimol}

Sedation was not observed in mice injected intracisternally or intrathecally with glycine, taurine, or muscimol (Table 2).

\section{Discussion}

The present study demonstrates that centrally administered glycine, taurine, or muscimol can produce analgesia and that $\mathrm{GABA}_{\mathrm{A}}$ receptor antagonists produce thermal hyperalgesia.
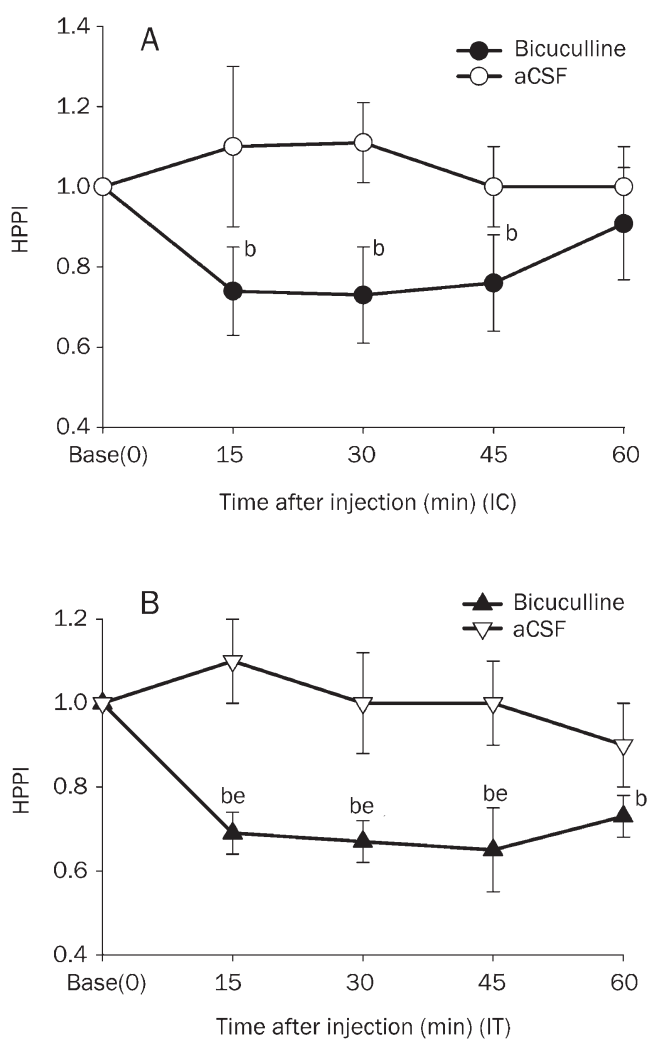

Figure 2. Effect of bicuculline or aCSF on HPPI. Bicuculline $(0.009 \mu \mathrm{g})$ or aCSF was injected intracisternally (IC, A) or intrathecally (IT, B). Data are expressed as means \pm SEM. ${ }^{b} P<0.05$ vs vehicle (aCSF) controls by the $t$-test; ${ }^{e} P<0.05$ vs basal time point (time $=0$ ) by repeated measures ANOVA ( $n=8$ mice per group).

On the other hand, glycine, muscimol, or intrathecal taurine was found to reduce bicuculline-induced allodynia, and to 

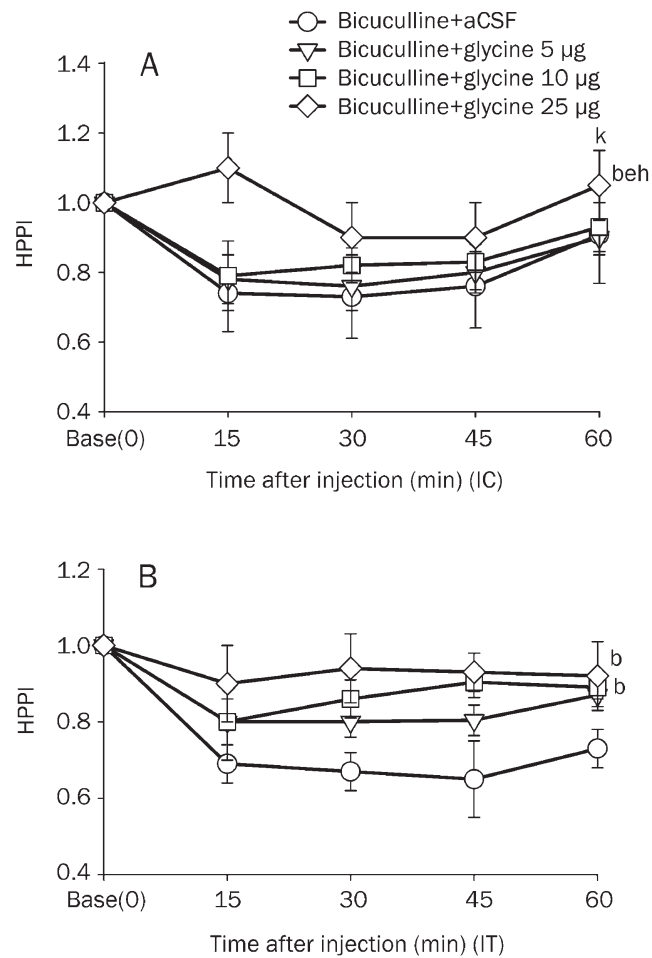

Figure 3. Effects of glycine on HPPI in bicuculline treated mice. Glycine (5, 10 , and $25 \mu \mathrm{g})$ with bicuculline $(0.009 \mu \mathrm{g})$ were injected intracisternally (IC, A) or intrathecally (IT, B). Data are expressed as means \pm SEMs. ${ }^{b} P<0.05$ vs the bicuculline+aCSF group, ${ }^{\mathrm{e}} P<0.05$ vs the bicuculline+glycine $5 \mu \mathrm{g}$ group, ${ }^{\text {h }} P<0.05$ vs the bicuculline+glycine $10 \mu$ g group by two-way ANOVA, Dunn's test, or the Holm-Sidak method ( $n=8$ mice per group). ${ }^{k} P<0.05$ vs basal time point (time $=0$ ), using two way ANOVA ( $n=8$ mice per group).

block bicuculline-induced thermal hyperalgesia. These results suggest that GABA and glycine work together to effect sensory modulation and that glycine and taurine are mediated by glycine and $\mathrm{GABA}_{\mathrm{A}}$ receptors. The present study suggests that
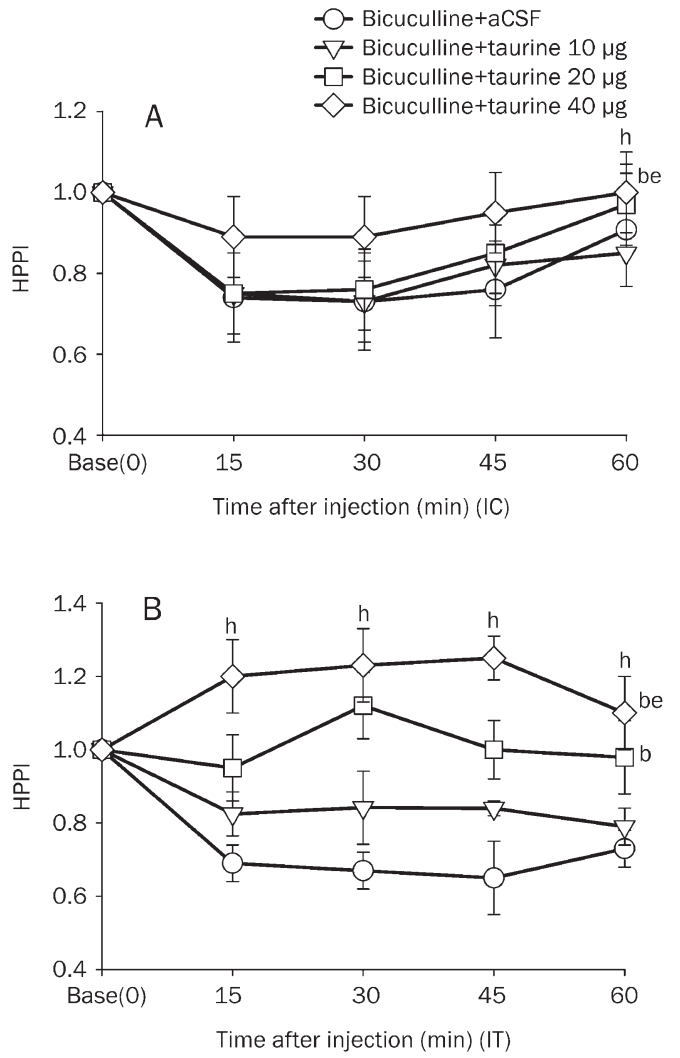

Figure 4. Effect of taurine on HPPI in bicuculline treated mice. Taurine (10, 20 , or $40 \mu \mathrm{g})$ with bicuculline $(0.009 \mu \mathrm{g})$ were injected intracisternally (IC, A) or intrathecally (IT, B). Data are expressed as means \pm SEMs. ${ }^{b} P<0.05$ vs the bicuculline+aCSF group, ${ }^{e} P<0.05$ vs the bicuculline+taurine $10 \mu \mathrm{g}$ group using two-way ANOVA, Dunn's test, or the Holm-Sidak method ( $n=8$ mice per group). ${ }^{\text {h }} P<0.05$ vs basal time point (time $=0$ ) by two way ANOVA ( $n=8$ mice per group).

glycine-related $\alpha$ - or $\beta$-amino acids or $\mathrm{GABA}_{\mathrm{A}}$ agonists are potential treatments for allodynia or hyperalgesia.

Table 2. Effects of intracisternal or intrathecal glycine, taurine, or muscimol on sedation (s).

\begin{tabular}{|c|c|c|c|c|c|}
\hline \multicolumn{6}{|c|}{ Intracisternal injection } \\
\hline Group & $(n=8$, each $)$ & Group & $(n=8$, each $)$ & Group & ( $n=8$, each) \\
\hline aCSF & $62 \pm 13$ & aCSF & $67 \pm 15$ & aCSF & $77 \pm 14$ \\
\hline Glycine 5 ug & $42 \pm 5$ & Taurine $10 \mu \mathrm{g}$ & $49 \pm 8$ & Muscimol $0.01 \mu \mathrm{g}$ & $71 \pm 16$ \\
\hline Glycine $10 \mu \mathrm{g}$ & $76 \pm 13$ & Taurine $20 \mu \mathrm{g}$ & $86 \pm 11$ & Muscimol $0.02 \mu \mathrm{g}$ & $89 \pm 16$ \\
\hline Glycine $25 \mu \mathrm{g}$ & $74 \pm 14$ & Taurine $40 \mu \mathrm{g}$ & $66 \pm 11$ & Muscimol $0.1 \mu g$ & $93 \pm 9$ \\
\hline \multicolumn{6}{|c|}{ Intrathecal injection } \\
\hline Group & $(n=8$, each $)$ & Group & $(n=8$, each $)$ & Group & $(n=8$, each $)$ \\
\hline aCSF & $55 \pm 12$ & aCSF & $68 \pm 14$ & aCSF & $54 \pm 13$ \\
\hline 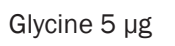 & $58 \pm 13$ & Taurine $10 \mu \mathrm{g}$ & $77 \pm 18$ & Muscimol $0.01 \mu \mathrm{g}$ & $84 \pm 17$ \\
\hline Glycine $10 \mu \mathrm{g}$ & $73 \pm 9$ & Taurine $20 \mu \mathrm{g}$ & $82 \pm 15$ & Muscimol $0.02 \mu \mathrm{g}$ & $91 \pm 12$ \\
\hline Glycine $25 \mu \mathrm{g}$ & $72 \pm 14$ & Taurine $40 \mu \mathrm{g}$ & $89 \pm 16$ & Muscimol $0.1 \mu g$ & $104 \pm 14$ \\
\hline
\end{tabular}

Values are expressed as means \pm SEMs ( $n=8$ mice per group). Each mouse was placed on a rubber cylinder after drug injection. Latency to step off the rubber cylinder with the hind paw was recorded. Data were analyzed using one-way ANOVA. No significant difference was observed between drug injected mice and vehicle (aCSF) controls. 

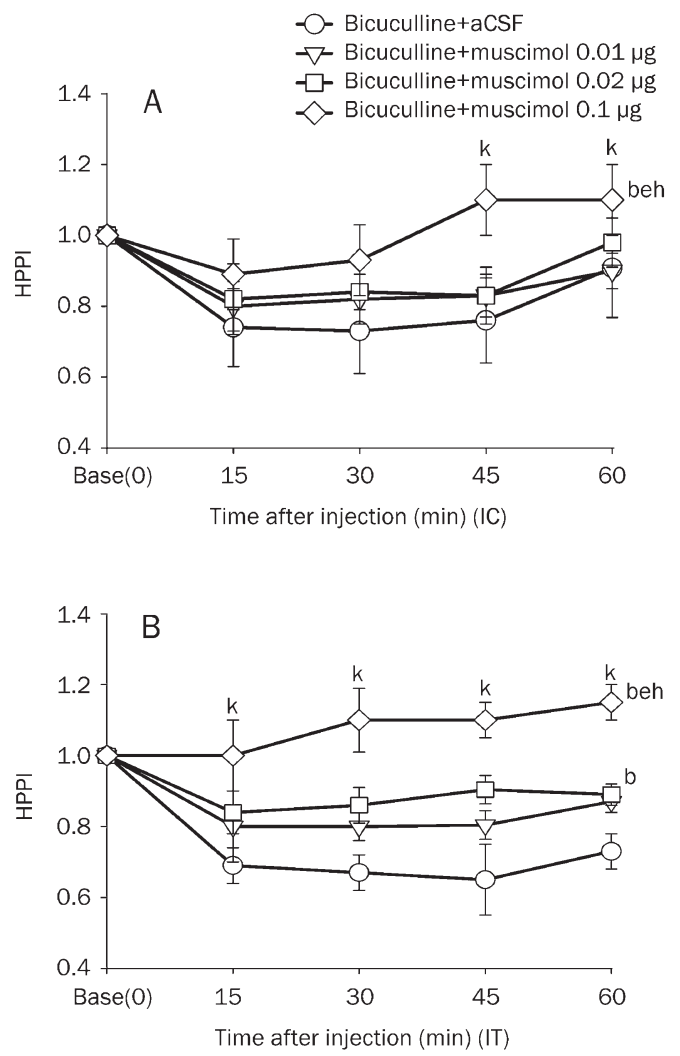

Figure 5. Effect of muscimol on HPPI in bicuculline treated mice. Muscimol $(0.01,0.02$, or $0.1 \mu \mathrm{g})$ with bicuculline $(0.009 \mu \mathrm{g})$ were injected intracisternally (IC, A) or intrathecally (IT, B). Data are expressed as means \pm SEMs. ${ }^{\mathrm{b}} P<0.05$ vs the bicuculline+aCSF group. ${ }^{\mathrm{e}} P<0.05$ vs the bicuculline+muscimol $0.01 \mu \mathrm{g}$ group, ${ }^{\mathrm{h}} P<0.05$ vs the bicuculline+muscimol $0.02 \mu \mathrm{g}$ group by two-way ANOVA, Dunn's test, or the Holm-Sidak method ( $n=8$ mice per group). ${ }^{k} P<0.05$ vs basal time point (time $=0$ ) by two way ANOVA ( $n=8$ mice per group).

\section{The anti-allodynic effects of glycine, taurine, and muscimol}

In the present study, glycine was found to reduce bicucullineinduced allodynia. This result is consistent with the finding that glycine and GABA are coreleased from the same interneurons ${ }^{[6]}$. Because spinal glycine and $\mathrm{GABA}_{\mathrm{A}}$ receptors are localized on the same postsynaptic membranes ${ }^{[4,5]}$, this finding suggests that GABA and glycine work together to affect sensory modulation. Furthermore, Todd and colleagues reported that both GABAergic and glycinergic neurons are present in spinal Rexed laminae II-IV and that fibers form axoaxonic synapses on $A \beta$ terminals and on the wide dynamic range neurons ${ }^{[5]}$. The authors also reported that glycine immunoreactivity in laminae I-III is restricted to neurons that also contain GABA and that $50 \%$ of the GABA-immunoreactive neurons also contain glycine ${ }^{[3,16]}$. In the present study, we found that blockade of $\mathrm{GABA}_{\mathrm{A}}$ receptors by centrally administered bicuculline evoked allodynia and that this effect is attenuated by glycine administration.

Our study also shows that intrathecal taurine reduced bicuculline-induced allodynia in our ICR mouse model. Although not directly comparable, the results of the present study are consistent with the results obtained by Jiang et al, namely, that taurine $(300 \mu \mathrm{mol})$ binds primarily to the glycine receptor; however, at high concentrations, taurine $(10 \mathrm{mmol})$ can also activate $\mathrm{GABA}_{\mathrm{A}}$ receptors in vitro ${ }^{[7]}$. In fact, Idrissi and Trenkner reported that taurine interacts directly with $\mathrm{GABA}_{\mathrm{A}}$ receptor in vitro ${ }^{[17]}$. These findings led us to speculate that $\mathrm{GABA}_{\mathrm{A}}$ receptor blockade might be modulated by taurine. However, $\mathrm{Xu}$ et al concluded that taurine activates glycine receptors rather than $\mathrm{GABA}_{\mathrm{A}}$ receptors ${ }^{[18]}$. Although no precise role has been defined for taurine during spinal nociceptive processing, it has been demonstrated that taurine inhibits the behaviors induced by intrathecal NMDA or kainate ${ }^{[8]}$. In the present study, we found that blockade of $\mathrm{GABA}_{\mathrm{A}}$ receptors by intrathecal bicuculline evoked allodynia and that this effect is attenuated by intrathecal taurine.

We also found that muscimol reduced bicuculline-induced allodynia, but it did not completely inhibit the effect of bicuculline in our model. We believe that this was due to the dose used, which was chosen specifically to have no effect on motor behavior in conscious mice. Muscimol can impair motor performance in the analgesic dose range (rat, intrathecal injection $0.5-1.0 \mu \mathrm{g})$, which is higher than that used in the present study. This result suggests that motor impairment may have impaired the vigorous scratching response or tail flick response to touch stimuli, thereby mimicking analgesia. Several lines of evidence have demonstrated that the stimulation of $\mathrm{GABA}_{\mathrm{A}}$ receptors by systemic or intracerebroventricular muscimol produces antinociception ${ }^{[19,20]}$. Although no direct comparison is possible, central GABA receptors have been demonstrated to participate in the production of antinociception, induced by the stimulation of descending pain inhibition systems. Our findings related to the effect of muscimol on allodynia are consistent with the results above. Furthermore, they indicate that bicuculline evokes allodynia and that muscimol attenuates this effect of bicuculline. Thus, the results of the present study indicate that $\mathrm{GABA}_{\mathrm{A}}$ receptors are involved in the modulation of pain behavior mediated by $\mathrm{GABA}_{\mathrm{A}}$ receptor antagonists.

\section{The anti-hyperalgesic effects of glycine, taurine, and muscimol}

Bicuculline was found to produce thermal hyperalgesia in the present study, which confirms the hypothesis that loss of GABA tone leads to hyperalgesia. The production of thermal hyperalgesia by bicuculline supports the hypothesis proposed by Yamamoto and Yaksh $^{[21]}$ that the loss of spinal bicucullinesensitive inhibition augments development of the thermal hyperalgesia induced by chronic nerve compression. The neural circuitries of thermal hyperalgesia and allodynia appear to differ. In particular, the afferent signals encoding allodynia appear to be encoded by large, myelinated afferent fibers, whereas the signals encoding thermal hyperalgesia are carried by small non-myelinated fibers ${ }^{[22]}$. Furthermore, thermal hyperalgesia seems to be mediated by pathways intrinsic to the spinal cord, whereas allodynia requires the contribution of supraspinal sites ${ }^{[23]}$. 
In the present study, intracisternal or intrathecal glycine, taurine, or muscimol significantly increased the bicucullineinduced pain threshold index, which is consistent with the finding of Simpson et al that intrathecal glycine reduced sensitivity to noxious stimulation ${ }^{[24]}$. We found that intracisternal taurine transiently inhibited bicuculline-induced thermal hyperalgesia, whereas intrathecal taurine inhibited this pathway for $60 \mathrm{~min}$. We believe that intracisternal administration allows better access to the brainstem and reduces the specificity of spinal cord activity. However, Simpson et al found that glycine reduced thermal hyperalgesia in rats after sciatic nerve ligation for more than $200 \mathrm{~min}$, whereas we observed this effect for only $60 \mathrm{~min}$ after intrathecal taurine administration. These differences are probably due to the different experimental models and species used. Furthermore, in the present study, intrathecal glycine failed to elicit any reduction in thermal hyperalgesia over the course of $60 \mathrm{~min}$, whereas intrathecal taurine reduced thermal hyperalgesia significantly over the course of $60 \mathrm{~min}$. According to another study, intrathecal bicuculline alone evokes a transient spinal release of taurine ${ }^{[25]}$, which suggests that intrathecal taurine could have a longer duration of action than glycine.

Some studies have shown that muscimol has an antinociceptive effect ${ }^{[26]}$, whereas muscimol is ineffective in the hotplate test ${ }^{[13,27]}$. These discrepancies regarding the effects of muscimol in mice may be due to species and drug-loading differences. Aanonsen et al administered muscimol at 0.05 pmol and bicuculline at 1 pmol intrathecally to reverse the inhibition of NMDA-induced tail-flick hyperalgesia induced by muscimol ${ }^{[26]}$. Hammond et al administered muscimol $(0.25$ $\mu \mathrm{g}$ ) intrathecally in the rat, but found that it did not have an anti-thermal hyperalgesic effect ${ }^{[27]}$. Minami et al administered muscimol $0.1 \mu \mathrm{g}$ intrathecally to reverse $0.01-0.1 \mu \mathrm{g}$ prostaglandin $\mathrm{E}_{2}$-induced heat hyperalgesia, but this approach was ineffective ${ }^{[13]}$. In the present study, we administered 0.01-0.1 $\mu \mathrm{g}$ muscimol $(0.25-25 \mu \mathrm{mol})$ and $0.009 \mu \mathrm{g}(5 \mu \mathrm{mol})$ bicuculline.

Analysis of the anti-hyperalgesia produced by muscimol is complicated by the motor effects of the drug. Muscimol impairs motor performance in the analgesic dose range, which suggests that motor impairment may have inhibited withdrawal from the hot plate and thus mimicked anti-hyperalgesia. Furthermore, our finding that muscimol did not produce significant motor dysfunction contrasts with those of previous studies, which found that muscimol produces motor weakness at analgesic doses ${ }^{[27]}$. Nevertheless, the present study shows that intracisternal or intrathecal $\mathrm{GABA}_{\mathrm{A}}$ receptor agonists produce intrinsic antinociception.

To summarize, glycine, taurine, and muscimol all reduced bicuculline-induced allodynia and thermal hyperalgesia responses in mice. Furthermore, their effects on thermal hyperalgesia were prolonged when administered intrathecally. Thus, glycine-related $\alpha$ - or $\beta$-amino acids and $\mathrm{GABA}_{\mathrm{A}}$ receptor agonists may prevent the binding of $\mathrm{GABA}_{\mathrm{A}}$ receptor antagonists in the central nervous system, which presents a possible strategy for the treatment of allodynia or hyperalgesia.

\section{Acknowledgements}

This work was supported by a Korean Research Foundation Grant funded by the Korean Government (MOEHRD) (KRF2006-531-E00062). The authors thank Professor Bernard A MacLeod, Craig R RIES, Stephan K SCHWARZ, and Ernest PUIL (Hugill Centre for Anesthesia and Analgesia, Department of Anesthesiology, Pharmacology \& Therapeutics, the University of British Columbia, Vancouver) for helpful advice and support during the course of this study. In addition, they would thank Helen CHUNG, Jimmy TC WANG, and Jaewoong HAN for valued technical support.

\section{Author contribution}

Il-ok LEE designed the research and wrote the paper; Eui-sung LIM undertook the research and performed the data analysis.

\section{References}

1 Curtis DR, Watkins JC. The excitation and depression of spinal neurons by structurally related amino acids. J Neurochem 1960; 6: $117-41$.

2 Chen YP, Chen SR, Pan HL. Effect of morphine on deep dorsal horn projection neurons depends on spinal GABAergic and glycinergic tone: implications for reduced opioid effect in neuropathic pain. J Pharmacol Exp Ther 2005; 315: 696-703.

3 Yaksh TL. Behavioral and autonomic correlates of the tactile evoked allodynia produced by spinal glycine inhibition: effects of modulatory receptor systems and excitatory amino acid antagonists. Pain 1989; 37: 119-23.

4 Mitchell K, Spike RC, Todd AJ. An immunocytochemical study of glycine receptor and GABA in laminae I-III of rat spinal dorsal horn. J Neurosci 1993; 13: 2371-81.

5 Todd AJ, Watt C, Spike RC, Sieghart W. Colocalization of GABA, glycine, and their receptors at synapses in the rat spinal cord. J Neurosci 1996; 16: 974-82.

6 Jonas P, Bischofberger J, Sandkühler J. Corelease of two fast neurotransmitters at a central synapse. Science 1998; 281: 419-24.

7 Jiang Z, Krnjević K, Wang F, Ye JH. Taurine activates strychninesensitive glycine receptors in neurons freshly isolated from nucleus accumbens of young rats. J Neurophysiol 2004; 91: 248-57.

8 Hornfeldt CS, Smullin DH, Schamber CD, Sun X, Larson AA. Antinociceptive effects of intrathecal taurine and calcium in the mouse. Life Sci 1992; 50: 1925-34.

9 Serrano JS, Serrano MI, Guerrero MR, Ruiz R, Polo J. Antinociceptive effect of taurine and its inhibition by naxolone. Gen Pharmacol 1990; 21: $333-6$.

10 Hylden JL, Wilcox GL. Intrathecal morphine in mice: a new technique. Eur J Pharmacol 1980; 67: 313-6.

11 Jobe PC, Dailey JW. Neurobiology of seizure predisposition in the genetically epilepsy prone rat. Proc West Pharmacol Soc 1991; 34: 223-5.

12 Loskota WJ, Lomax P, Rich ST. The gerbil as a model for the study of the epilepsies. Seizure patterns and ontogenesis. Epilepsia 1974; 15: 109-19.

13 Minami T, Nishihara I, Ito S, Sakamoto K, Hyodo M, Hayaishi O. Nitric oxide mediates allodynia induced by intrathecal administration of prostaglandin E2 or prostaglandin F2 alpha in conscious mice. Pain 1995; 61: 285-90.

14 Minami T, Uda R, Horiguchi S, Ito S, Hyodo M, Hayaishi O. Allodynia evoked by intrathecal administration of prostaglandin E2 to conscious 
mice. Pain 1994; 57: 217-23.

15 Porreca F, Mosberg HI, Omnaas JR, Burks TF, Cowan A. Supraspinal and spinal potency of selective opioid agonists in the mouse writhing test. J Pharmacol Exp Ther 1987; 240: 890-4.

16 Todd AJ. GABA and glycine in synaptic glomeruli of the rat spinal dorsal horn. Eur J Neurosci 1996; 8: 2492-8.

17 El Idrissi A, Trenkner E. Growth factors and taurine protect against excitotoxicity by stabilizing calcium homeostasis and energy metabolism. J Neurosci 1999; 19: 9459-68.

$18 \mathrm{Xu} \mathrm{H}$, Zhou KQ, Huang YN, Chen L, Xu TL. Taurine activates strychnine-sensitive glycine receptors in neurons of the rat inferior colliculus. Brain Res 2004; 1021: 232-40.

19 Hill RC, Maurer R, Buescher HH, Roemer D. Analgesic properties of the GABA-mimetic THIP. Eur J Pharmacol 1981; 69: 221-4

20 Liebman JM, Pastor G. Antinociceptive effects of baclofen and muscimol upon intraventricular administration. Eur J Pharmacol 1980; 61: 225-30.

21 Yamamoto T, Yaksh TL. Effects of intrathecal strychnine and bicuculline on nerve compression-induced thermal hyperalgesia and selective antagonism by MK-801. Pain 1993; 54: 79-84.
22 Ossipov MH, Bian D, Malan TP Jr, Lai J, Porreca F. Lack of involvement of capsaicin-sensitive primary afferents in nerve-ligation injury induced tactile allodynia in rats. Pain 1999; 79: 127-33.

23 Bian D, Ossipov MH, Zhong C, Malan TP Jr, Porreca F. Tactile allodynia, but not thermal hyperalgesia, of the hindlimbs is blocked by spinal transection in rats with nerve injury. Neurosci Lett 1998; 241: 79-82.

24 Simpson RK Jr, Gondo M, Robertson CS, Goodman JC. Reduction in thermal hyperalgesia by intrathecal administration of glycine and related compounds. Neurochem Res 1997; 22: 75-9.

25 Ishikawa T, Marsala M, Sakabe T, Yaksh TL. Characterization of spinal amino acid release and touch-evoked allodynia produced by spinal glycine or $\operatorname{GABA}(A)$ receptor antagonist. Neuroscience 2000; 95: 781-6.

26 Aanonsen LM, Wilcox GL. Muscimol, gamma-aminobutyric acid re- $^{2}$ ceptors and excitatory amino acids in the mouse spinal cord. J Pharmacol Exp Ther 1989; 248: 1034-8.

27 Hammond DL, Drower EJ. Effects of intrathecally administered THIP, baclofen and muscimol on nociceptive threshold. Eur J Pharmacol 1984; 103: 121-5. 